Article

\title{
Restrained Eating and Vegan, Vegetarian and Omnivore Dietary Intakes
}

\author{
Anna Brytek-Matera \\ Institute of Psychology, University of Wroclaw, Dawida 1, 50-527 Wroclaw, Poland; \\ anna.brytek-matera@uwr.edu.pl
}

Received: 5 June 2020; Accepted: 15 July 2020; Published: 17 July 2020

\begin{abstract}
There are a significant number of studies on cognitive restraint among individuals with varying dietary patterns. Although most research has found that vegetarians report higher levels of cognitive restraint compared to non-vegetarians, many studies have contributed inconsistent results. The aim of the current study, therefore, was to assess any differences between groups with varying dietary patterns on cognitive restraint and other disordered eating pattern. The second objective was to examine determinants of cognitive restraint in individuals adhering to a vegan diet, a vegetarian diet and an omnivore diet. Two-hundred and fifty-four participants with varying dietary patterns completed the Three-Factor Eating Questionnaire, the Perseverative Thinking Questionnaire and the Eating Habits Questionnaire. Our results indicated that both vegetarian and vegan groups showed a significantly lower cognitive restraint, lower emotional eating and lower uncontrolled eating than those who followed an omnivorous diet. In addition, these both groups following a plant-based diet have shown more cognitions, behaviours and feelings related to an extreme focus on healthy eating (orthorexia nervosa) than group following an omnivorous diet. There were no significant differences between the groups in perseverative thinking. Core characteristics of repetitive negative thinking was a significant predictor of cognitive restraint in vegans. Feeling positively about healthy eating predicted cognitive restraint among vegetarians. Problems associated with healthy eating and feeling positively about healthy eating predicted cognitive restraint among individuals following an omnivorous diet. Knowledge of predictors of cognitive restraint may serve as a psychological intervention goal or psychoeducation goal among individuals with varying dietary patterns.
\end{abstract}

Keywords: vegetarian diet; vegan diet; cognitive restraint; repetitive negative thinking; orthorexia nervosa

\section{Introduction}

A healthy vegetarian eating pattern provides recommendations to meet the dietary guidelines for those who follow a meat-free diet [1]. The healthy vegetarian eating pattern includes increased intake of legumes (beans and peas), soy products (particularly tofu and other processed soy products), nuts and seeds and whole grains. It contains no meats, poultry or seafood. In contrast to a vegetarian diet, a vegan diet excludes (a) animal products (eggs, dairy, beeswax and honey, leather products and goose-fat shoe polish); (b) garlic, onion, spring onion, scallions and leeks (c) products that may contain animal ingredients not included in their labels or which use animal products in their manufacturing, e.g., cheeses that use animal rennet (enzymes from animal stomach lining), gelatin (from animal skin, bones and connective tissue); (d) some sugars that are whitened with bone char (e.g., cane sugar but not beet sugar) [2].

The decision to adhere to a vegetarian diet is reported to be influenced by ethics reasons (e.g., moral considerations), health reasons (e.g., concern for potential disease, control of weight), concern 
about animal welfare (distaste for meat), preference for vegetarian food and/or religious and cultural beliefs [2-4].

Vegetarianism is restrictive by nature, regardless of any co-occurring eating pathology [5]. There are two distinct theories that explain dietary restraint [6]. The first, called the boundary model [7], explains how restrained eating can lead to unsuccessful dieting (dieting equals dietary restraint). Many diets fail due to the disinhibition of restraint effect (also known as the 'what the hell' effect). That is where a person is forced to violate her/his self-imposed restraint through eating forbidden foods or overconsuming calories (often in response to emotional distress) and continues to eat more than she/he usually would. In contrast, individuals who do not follow strict dietary rules tend to not have forbidden foods and when forced to overconsume on calories tend to compensate by eating less at the next meal. The second theory, a three-factor model of dieting behaviour [8] (frequency of dieting and overeating, current dieting and weight suppression) postulates that dietary restraint develops as the result of frequent dieting and overeating in the past rather than from current weight loss dieting or cognitive restraint. This model caused confusion in the restraint literature as to whether restraint is a measure of current restriction or a measure of dieting and overeating history [9]. Nowadays, it is generally accepted that dietary restraint is a construct that includes why a person is dieting ("restraint" is often explained as a long-term or habitual pattern of eating behaviour [9]), while dieting itself is the observed behaviour of restricting or intending to restrict, calories [6].

Cognitive restraint is defined as the mental effort applied to modify eating behaviours in order to maintain a restrictive dietary pattern [10]. In other words, it is the intention to control food intake in order to maintain or lose weight. Previous studies focusing on differences between vegetarians and omnivores have shown inconsistent results. Several studies have suggested higher cognitive restraint scores in vegetarians, others have found evidence for higher cognitive scores in non-vegetarians, and others have not found any differences between the two groups for this construct (Table 1).

Table 1. Cognitive restraint scores between vegetarians and omnivores: the inconsistent results.

\begin{tabular}{|c|c|c|}
\hline $\begin{array}{l}\text { Higher Cognitive Restraint Scores } \\
\text { in Vegetarians }\end{array}$ & $\begin{array}{l}\text { Higher Cognitive Restraint } \\
\text { Scores in Non-Vegetarians }\end{array}$ & $\begin{array}{c}\text { Not Difference in Cognitive Restraint } \\
\text { between the Two Groups }\end{array}$ \\
\hline $\begin{array}{c}\text { Barr et al. }[11]^{* *} \\
N \text { vegetarians }=23 \\
N \text { non-vegetarians }=22 \\
\text { Method: The Three-Factor Eating } \\
\text { Questionnaire }\end{array}$ & $\begin{array}{c}\text { Brytek-Matera [12]* } \\
N \text { vegetarians }=188 \\
N \text { non-vegetarians }=182 \\
\text { Method: The Three-Factor Eating } \\
\text { Questionnaire (TFEQ-R18) }\end{array}$ & $\begin{array}{c}\text { Barr and Broughton }[13]^{*} \\
N \text { current vegetarians }=90 \\
N \text { past vegetarians }=35 \\
N \text { non-vegetarians }=68 \\
\text { Method: Multiple-pass } 24-\mathrm{h} \text { diet recall }\end{array}$ \\
\hline $\begin{array}{l}\text { Gilbody et al. [14] }{ }^{*} \\
N \text { total = } 131 \text { young adults women } \\
\text { Method: the Dutch Eating Behavior } \\
\text { Questionnaire }\end{array}$ & $\begin{array}{l}\text { Curtis and Comer [15] } \\
N \text { total }=90 \text { female undergraduate } \\
\text { students and community members } \\
\text { Method: The Three-Factor Eating } \\
\text { Questionnaire }\end{array}$ & $\begin{array}{c}\text { Barthels et al. }[16]^{*} \\
N \text { vegetarians }=63 \\
N \text { vegans }=114 \\
N \text { non-vegetarians }=182 \\
\text { Method: the Restraint Eating Scale }\end{array}$ \\
\hline $\begin{array}{l}\text { Martins et al. }[17] * \\
N \text { vegetarians }=70 \\
N \text { non-vegetarians }=105 \\
N \text { semi-vegetarians }=49 \\
\text { Method: The Three-Factor Eating } \\
\text { Questionnaire }\end{array}$ & $\begin{array}{c}\text { Janelle and Barr }[18]^{*} \\
N \text { vegetarians }=23\end{array}$ & $\begin{array}{c}\text { Brytek-Matera et al. }[19]^{*} \\
N \text { vegetarians }=39 \\
N \text { vegans }=40 \\
N \text { non-vegetarians }=174 \\
\text { Method: The Three-Factor Eating } \\
\text { Questionnaire (TFEQ-R18) }\end{array}$ \\
\hline $\begin{array}{c}\text { McLean and Barr [20]* } \\
N \text { total = } 1350 \text { female university } \\
\text { students } \\
\text { Method: The Three-Factor Eating } \\
\text { Questionnaire }\end{array}$ & $\begin{array}{c}N \text { non-vegetarians }=22 \\
\text { Method: The Three-Factor Eating } \\
\text { Questionnaire }\end{array}$ & $\begin{array}{c}\text { Fisak et al. }[21]^{*} \\
N \text { vegetarians }=52 \\
N \text { non-vegetarians }=204 \\
\text { Methods: the Dutch Eating Behavior } \\
\text { Questionnaire and the Three-Factor } \\
\text { Eating Questionnaire }\end{array}$ \\
\hline
\end{tabular}


Table 1. Cont.

\begin{tabular}{|c|c|c|}
\hline $\begin{array}{c}\text { Higher Cognitive Restraint Scores } \\
\text { in Vegetarians }\end{array}$ & $\begin{array}{l}\text { Higher Cognitive Restraint } \\
\text { Scores in Non-Vegetarians }\end{array}$ & $\begin{array}{c}\text { Not Difference in Cognitive Restraint } \\
\text { between the Two Groups }\end{array}$ \\
\hline $\begin{array}{c}\text { Trautman et al. }[22]^{*} \\
N \text { total }=330 \text { college students } \\
\text { Method: the Dutch Eating Behavior } \\
\text { Questionnaire }\end{array}$ & & $\begin{array}{c}\text { Forestell et al. }[23]^{*} \\
N \text { vegetarians }=55 \\
N \text { pesco-vegetarians }=28\end{array}$ \\
\hline $\begin{array}{c}\text { Worsley and Skrzypiec [24] }{ }^{*} \\
N \text { total = } 2000 \text { senior secondary school } \\
\text { students } \\
\text { Method: the Food Frequency } \\
\text { Questionnaire }\end{array}$ & & $\begin{array}{c}N \text { semi-vegetarians }=29 \\
N \text { flexitarians }=37 \\
N \text { non-vegetarians }=91 \\
\text { Method: The Three-Factor Eating } \\
\text { Questionnaire }\end{array}$ \\
\hline
\end{tabular}

Cognitive restraint is frequently used as a marker of pathological eating behaviours taking into consideration its consequences: dysregulation of internal perceptions of hunger and satiety, disinhibition which results in overeating, emotional dysregulation, low self-esteem and low body satisfaction [12].

Vegetarianism appears to be disproportionately associated with disordered eating [5]. However, the relationship is complex and the causality between cognitive restraint and vegetarianism is difficult to prove because: (a) current measures of cognitive restraint may inadequately measure restrictive behaviours in vegetarians and they could overestimate pathological eating behaviours in this group, (b) some vegetarians may score higher on measures of cognitive restraint because they restrict animal products on a daily basis, and not due to disordered eating behaviours [5].

One of the inappropriate eating behaviours among individuals with varying dietary patterns is orthorexia nervosa. This disordered eating pattern is characterized by a pathological fixation on consuming foods based on their quality (rather than their quantity) for achieving optimal health and/or avoiding illness $[25,26]$. Orthorexia nervosa is associated with avoidance of certain food groups (i.e., carbohydrates and fats), avoidance of foods with artificial substances and food prepared with the use of herbicides or pesticides [27], deleterious health behaviours (e.g., nutritional deficits, starvation) [28] and psychological consequences (e.g., social isolation, low quality of life, excessive fear and worries related to healthy dietary intake) $[29,30]$. Nowadays, there is a lack of consensus regarding the link between a vegetarian diet and orthorexia nervosa [31]. Nevertheless, it is worth pointing out that the latest literature review [31] have shown that vegetarian diet adherence was related to orthorexia nervosa (in 11 out of 14 studies published within the last five years). Furthermore, in seven studies (out of 14), vegetarians in the general population have been found to report more orthorexia nervosa or to be at risk of developing orthorexia nervosa than non-vegetarians.

Orthorexia nervosa shares several characteristics with vegetarianism, veganism and dieting behaviour (e.g., specific food selection-consuming healthy and organic food, focusing on quality of food intake, reduction of food intake according to specific nutrition rules, nutrition rules specifying which foods are "allowed" and which are "forbidden, rigid food rules and an inability to remain flexible in one's eating habits) [19]. All of these dietary patterns include restrictions which resemble cognitive restraint. The continuous reduction of "allowed" foods results in a diet with only very few foods considered edible [16]. It is worth pointing out that recent study has shown that orthorexia nervosa can interfere with cognitive restraint [19] as well as that plant-based diet might be a contributing factor for the onset of orthorexia nervosa [16].

Extreme pursuit of healthy eating often lead to obsessive thoughts about food [32]. Repetitive negative thinking is a style of thinking about one's problems (current, past or future) or negative experiences (past or anticipated) which are characterized by repetitiveness, intrusiveness and difficulty in disengaging from (the actual thinking process) [33]. In addition, repetitive negative thinking captures mental capacity and individuals perceive it as unproductive (individuals' perceived dysfunctional effects of repetitive negative thinking). To the best of our knowledge, there is only one 
study examining the difference between vegetarians and non-vegetarians in the field [34]. Vegetarians showed more daily repetitive negative thinking than omnivores.

Although the perception of a relationship between vegetarianism and cognitive restraint remains widespread, there is presently no compelling empirical evidence to suggest that vegetarians are at greater risk of disordered eating behaviours compared to omnivores [5,35]. Therefore, the objectives of the present study were to: (1) investigate any differences between groups with varying dietary patterns on cognitive restraint and other disordered eating pattern; and (2) assess determinants of cognitive restraint among adults with varying dietary patterns (vegan, vegetarian and omnivore dietary styles).

On the basis of the literature, we put forward the following hypotheses:

Hypothesis 1 (H1). Individuals adhering to plant-based diet (vegan and vegetarian diet) have lower levels of cognitive restraint than those adhering to an omnivorous diet.

Hypothesis 2 (H2). Individuals following a vegetarian and a vegan diet present a higher level of orthorexic behaviours compared to the individuals following a meat diet.

Hypothesis 3 (H3). A disordered eating pattern (orthorexia nervosa) is a predictor of cognitive restraint among individuals following a vegetarian and vegan diet.

Hypothesis 4 (H4). Repetitive negative thinking is a predictor of cognitive restraint among individuals following a vegetarian and vegan diet.

Results of the present study could contribute to identifying potential factors for cognitive restraint and to gain a better insight into dietary patterns in general.

\section{Materials and Methods}

\subsection{Participants and Study Design}

Internet-based surveys are often used in psychology and health research (e.g., [36]). To collect the data, an online survey (SurveyMonkey ${ }^{\circledR}$ ) was created and used. Participants were recruited through: (a) flyers distributed to local health food stores, vegan or vegetarian restaurants, (b) fitness centers, (c) universities and (d) through the internet (e.g., vegan or vegetarian social networking). Of the 308 individuals who began the questionnaires, finally $254(82.46 \%)$ completed the survey and met the inclusion criteria (47 participants following a vegan diet, 100 participants following a vegetarian diet and 107 participants following an omnivorous diet). Eligibility criteria included both inclusion and exclusion criteria and comprised age (at least 18 years of age); consistency of self-defined types of diet (a "yes/no" item) and objective criteria for vegetarianism (exclusion of animal-derived foods such as meat, poultry and fish from the diet), veganism (exclusion of all animal products from the diet including dairy, cheese and eggs; a diet based solely on plant-based food) and an omnivorous diet (inclusion of animal and plant foods); and following a vegetarian or vegan diet for at least 12 months. All participants who met the inclusion criteria listed above were selected for the present study. Participants who answered in the affirmative were asked a number of other questions regarding the type of vegetarian diet, reasons for beginning and maintaining the diet and length of time the diet has been followed. Participants $(5.84 \%, N=18)$ were excluded from the study because of a discrepancy between self-identification and objective criteria (e.g., those who described themselves as vegetarians and declared sometimes eating meat or fish were eliminated). The procedure was presented in our previous publication [37]. The present study has been approved by a research ethics committee (No. WKEB45/03/2017). All procedures performed in our study were in accordance with the 1964 Helsinki declaration (adopted by the 18th World Medical Association General Assembly, Helsinki, Finland) and its later amendments or comparable ethical standards. The research project was funded by the National Science Centre (NCN), Poland (Grant no. 2017/01/X/HS6/00007). The current 
study was part of a large project focusing on the assessment of repetitive negative thinking and eating behaviours in daily life among individuals with varying dietary patterns.

\subsection{Outcome Measures}

Eating behaviours (The Three-Factor Eating Questionnaire [37]), repetitive negative thinking (the Perseverant Thinking Questionnaire [33]) as well as cognitions, behaviours and feelings related to orthorexia nervosa (the Eating Habits Questionnaire [38]) were measured in the present study (Table 2). All questionnaires used in the present study were formatted using a commercial online survey utility provided by Survey Monkey ${ }^{\circledR}$.

Table 2. Characteristics of measurements used in the present study.

\begin{tabular}{|c|c|c|c|c|}
\hline Questionnaire & Objective & $\begin{array}{l}\text { Number } \\
\text { of Items }\end{array}$ & Subscales & $\begin{array}{l}\text { Internal Reliability: } \\
\text { Cronbach's } \alpha\end{array}$ \\
\hline $\begin{array}{l}\text { The Polish version } \\
\text { of the Three-Factor } \\
\text { Eating } \\
\text { Questionnaire [39] }\end{array}$ & $\begin{array}{l}\text { Assessment of } \\
\text { three different } \\
\text { aspects of eating } \\
\text { behaviours }\end{array}$ & 18 & $\begin{array}{l}\text { 1. Cognitive restraint-conscious } \\
\text { restriction of food intake in order to } \\
\text { control body weight or to promote } \\
\text { weight loss. } \\
\text { 2. Uncontrolled eating-tendency to } \\
\text { eat more than usual due to a loss of } \\
\text { control over intake accompanied by } \\
\text { subjective feelings of hunger. } \\
\text { 3. Emotional eating-inability to resist } \\
\text { emotional cues, the tendency to eat in } \\
\text { response to negative emotions. }\end{array}$ & $\begin{array}{c}\text { Cognitive restraint: } \\
\alpha=0.78 \\
\text { Uncontrolled eating: } \\
\alpha=0.84 \\
\text { Emotional eating: } \\
\alpha=0.86\end{array}$ \\
\hline $\begin{array}{c}\text { The Polish version } \\
\text { of the Perseverative } \\
\text { Thinking } \\
\text { Questionnaire [40] }\end{array}$ & $\begin{array}{l}\text { Assessment of } \\
\text { repetitive negative } \\
\text { thinking from a } \\
\text { content-independent } \\
\text { perspective }\end{array}$ & 15 & $\begin{array}{l}\text { 1. Core characteristics of repetitive } \\
\text { negative thinking: (a) repetitiveness, } \\
\text { (b) intrusiveness and (c) difficulties to } \\
\text { disengagement. } \\
\text { 2. Unproductiveness of repetitive } \\
\text { negative thinking. } \\
\text { 3. Capturing mental capacity. }\end{array}$ & $\begin{array}{c}\text { Cronbach's } \\
\alpha=0.64-0.92\end{array}$ \\
\hline $\begin{array}{l}\text { The Polish version } \\
\text { of the Eating } \\
\text { Habits } \\
\text { Questionnaire [19] }\end{array}$ & $\begin{array}{c}\text { Assessment of } \\
\text { cognitions } \\
\text { behaviours and } \\
\text { feelings related to } \\
\text { an extreme focus } \\
\text { on healthy eating, } \\
\text { which has been } \\
\text { called orthorexia } \\
\text { nervosa }\end{array}$ & 21 & $\begin{array}{l}\text { 1. Knowledge of healthy eating. } \\
\text { 2. Problems associated with healthy } \\
\text { eating. } \\
\text { 3. Feeling positively about healthy } \\
\text { eating. }\end{array}$ & $\begin{array}{c}\text { Knowledge of healthy } \\
\text { eating: } \\
\alpha=0.81 \\
\text { Problems associated } \\
\text { with healthy eating: } \\
\alpha=0.82 \\
\text { Feeling positively } \\
\text { about healthy eating: } \\
\alpha=0.82\end{array}$ \\
\hline
\end{tabular}

In addition, the participants were asked questions regarding age, anthropometry (weight and height), health and lifestyle status (type of special diet, level of physical activity) and eating habits (number of meals consumed per day, daily water intake, dietary supplement consumption and type of supplement consumed, main reason why participants decided to follow a plant-based diet and main reason why participants are following a plant-based diet as well). All this information was obtained using a questionnaire specially designed for this study (the statistics presented in Table 3 are based on replies obtained in this questionnaire).

Intensity of physical activity (moderate- and vigorous-intensity physical activity) was based on the World Health Organization's (WHO) recommendation on physical activity for adults aged 18-64 [41]: at least $150 \mathrm{~min}$ of moderate-intensity physical activity throughout the week and at least $75 \mathrm{~min}$ of vigorous-intensity physical activity throughout the week. In addition, the number of hours spent on different physical activity levels were obtained and converted into metabolic equivalents (METs). Average METs for moderate physical activity is equal to 4.0 and for vigorous physical activity is equal 8.0. Using these values, the scores expressed as MET-minutes/week were defined as: (a) moderate MET-minutes/week $=4.0$ (intensity level) * moderate-intensity activity minutes (duration of activity) * 
moderate days (frequency of activity) and (b) vigorous MET-minutes/week $=8.0$ * vigorous-intensity activity minutes * vigorous-intensity days [42]. Moderate-intensity physical activity was obtained by taking into account 5 or more days of any combination of walking, moderate-intensity or vigorous intensity activities achieving a minimum total physical activity of at least 600 MET-minutes/week. However, vigorous-intensity physical activity was computed by using 7 or more days of any combination of walking, moderate-intensity or vigorous-intensity activities achieving a minimum total physical activity of at least 3000 MET-minutes/week [42].

Due to the nature of the study (a web-based survey), types of physical measurements (height, weight and body mass index (BMI)) were self-reported (we were unable to invite participants to take direct measurements and use standard laboratory measurement, e.g., dual-energy X-ray absorptiometry, bioelectrical impedance analysis). BMI was calculated for self-reported values.

\section{Results}

\subsection{Statistical Analysis}

Statistical analyses were carried out using the Statistical Package for Social Sciences 25.0 (SPSS, Chicago, IL, USA). Associations with categorical variables (independent variable: dietary patterns; dependent variables: eating behaviours, repetitive negative thinking, orthorexia nervosa) were investigated with one-way analysis of variance (ANOVA) (comparison between participants following a vegan diet, vegetarian diet and omnivorous diet). Partial $\eta 2$ was calculated as measure of effect size. Associations with continuous variables were examined with Pearson's r correlation coefficients (relationship between cognitive restraint and orthorexia nervosa and repetitive negative thinking across the dietary patterns). To predict cognitive restraint a multiple linear regression analysis was used (predictors of cognitive restraint among individuals with varying dietary patterns).

\subsection{Characteristics of the Study Population}

Descriptive characteristics of the participants are presented in Table 3.

Table 3. Descriptive characteristics of the study population.

\begin{tabular}{|c|c|c|c|}
\hline Variable & $\begin{array}{c}\text { Vegan Diet } \\
N=47\end{array}$ & $\begin{array}{l}\text { Vegetarian Diet } \\
\quad N=100\end{array}$ & $\begin{array}{c}\text { Omnivorous Diet } \\
\qquad N=107\end{array}$ \\
\hline & & \multicolumn{2}{|c|}{ Mean (SD) } \\
\hline Age & $30.61(11.64)$ & $28.39(8.92)$ & $28.72(9.87)$ \\
\hline Body mass index $\left(\mathrm{kg} / \mathrm{m}^{2}\right)$ & $21.46(4.10)$ & $21.97(2.88)$ & $23.01(5.35)$ \\
\hline \multirow[t]{2}{*}{ Following plant-based diet (in moths) } & $44.40(62.30)$ & $82.90(102.36)$ & - \\
\hline & & \multicolumn{2}{|c|}{$N(\%)$} \\
\hline \multicolumn{4}{|l|}{ Number of meals consumed per day } \\
\hline 1 & $0(0.0)$ & $0(0)$ & $2(1.9)$ \\
\hline 2 & $2(4.3)$ & $4(4)$ & $5(4.7)$ \\
\hline 3 & $16(34.0)$ & $20(20)$ & $27(25.2)$ \\
\hline 4 & $19(40.4)$ & $38(38)$ & $49(45.8)$ \\
\hline 5 & $9(19.2)$ & $30(30)$ & $20(18.7)$ \\
\hline More than 5 & $1(2.1)$ & $8(8)$ & $4(3.7)$ \\
\hline \multicolumn{4}{|l|}{ Daily water intake } \\
\hline Less than $1 \mathrm{~L}$ & $2(4.2)$ & $2(2)$ & $18(16.8)$ \\
\hline From $1 \mathrm{~L}$ to $1,4 \mathrm{~L}$ & $7(14.9)$ & $22(22)$ & $40(37.4)$ \\
\hline $1,5 \mathrm{~L}$ & 7 (14.9) & $29(29)$ & $18(16.8)$ \\
\hline From $1,6 \mathrm{~L}$ to $1,9 \mathrm{~L}$ & $4(8.5)$ & $3(3)$ & $3(2.8)$ \\
\hline $2 \mathrm{~L}$ & $15(31.9)$ & $25(25)$ & $21(19.6)$ \\
\hline From $2,1 \mathrm{~L}$ to $2,4 \mathrm{~L}$ & $2(4.3)$ & $3(3)$ & $0(0)$ \\
\hline $2,5 \mathrm{~L}$ & $1(2.1)$ & $9(9)$ & $3(2.8)$ \\
\hline
\end{tabular}


Table 3. Cont.

\begin{tabular}{|c|c|c|c|}
\hline Variable & $\begin{array}{l}\text { Vegan Diet } \\
\qquad N=47\end{array}$ & $\begin{array}{l}\text { Vegetarian Diet } \\
\quad N=100\end{array}$ & $\begin{array}{c}\text { Omnivorous Diet } \\
N=107\end{array}$ \\
\hline $3 \mathrm{~L}$ & $6(12.8)$ & $4(4)$ & $3(2.8)$ \\
\hline $3,5 \mathrm{~L}$ & $0(0)$ & $1(1)$ & $1(0.9)$ \\
\hline $4 \mathrm{~L}$ & $3(6.4)$ & $2(2)$ & $0(0.0)$ \\
\hline \multicolumn{4}{|l|}{ Dietary supplement consumption } \\
\hline Yes & $34(72.3)$ & $59(59)$ & $25(23.4)$ \\
\hline No & $13(27.7)$ & $41(41)$ & $82(76.6)$ \\
\hline \multicolumn{4}{|l|}{$\begin{array}{l}\text { Type of supplement consumed } \\
\text { (multiple choice question) }\end{array}$} \\
\hline Vitamin D & $21(44.7)$ & $32(32)$ & $12(11.2)$ \\
\hline Vitamin B12 & $29(61.7)$ & $34(34)$ & $4(3.7)$ \\
\hline Vitamin C & $1(2.1)$ & $10(10)$ & $2(1.9)$ \\
\hline Magnesium & $4(8.5)$ & $13(13)$ & $8(7.5)$ \\
\hline \multicolumn{4}{|l|}{ Moderate-intensity physical activity } \\
\hline Never & $0(0)$ & $0(0)$ & $9(8.4)$ \\
\hline One per week & $5(10.6)$ & $6(6)$ & $42(39.2)$ \\
\hline Twice per week & $0(0)$ & $13(13)$ & $0(0)$ \\
\hline 3 per week & $7(14.9)$ & $25(25)$ & $23(21.5)$ \\
\hline 5 per week & $10(21.3)$ & $18(18)$ & $14(13.1)$ \\
\hline Every day & $25(53.2)$ & $38(38)$ & $19(17.8)$ \\
\hline \multicolumn{4}{|l|}{ Vigorous-intensity Physical Activity } \\
\hline Never & $16(34.04)$ & $44(44)$ & $51(47.7)$ \\
\hline One per week & $15(31.91)$ & $30(30)$ & $37(34.6)$ \\
\hline Twice per week & $0(0)$ & $0(0)$ & $0(0)$ \\
\hline 3 per week & $10(21.30)$ & $20(20)$ & $14(13.1)$ \\
\hline 5 per week & $4(8.51)$ & $6(6)$ & $4(3.7)$ \\
\hline Every day & $2(4.30)$ & $0(0)$ & $1(0.9)$ \\
\hline \multicolumn{4}{|l|}{$\begin{array}{l}\text { Main reason why participants decided } \\
\text { to follow a plant-based diet }\end{array}$} \\
\hline Animal welfare & $25(53.20)$ & $60(60)$ & \multirow{8}{*}{ Not applicable } \\
\hline Health & $10(21.30)$ & $10(10)$ & \\
\hline Ethics & $4(8.51)$ & $9(9)$ & \\
\hline Care for the natural environment & $2(4.25)$ & $9(9)$ & \\
\hline Religion & $1(2.12)$ & $0(0)$ & \\
\hline Economic considerations & $1(2.12)$ & $0(0)$ & \\
\hline Weight loss & $2(4.25)$ & $0(0)$ & \\
\hline Other reason & $2(4.25)$ & $12(12)$ & \\
\hline \multicolumn{4}{|l|}{$\begin{array}{l}\text { Main reason why participants are } \\
\text { following a plant-based diet }\end{array}$} \\
\hline Animal welfare & $29(61.6)$ & $53(53)$ & \multirow{6}{*}{ Not applicable } \\
\hline Health & $6(12.8)$ & $13(13)$ & \\
\hline Ethics & $6(12.8)$ & $17(17)$ & \\
\hline Care for the natural environment & $3(6.4)$ & $7(7)$ & \\
\hline Religion & $1(2.1)$ & $0(0)$ & \\
\hline Other reason & $2(4.3)$ & $10(10)$ & \\
\hline
\end{tabular}

No significant between-group difference was observed in terms of age, $F(2,251)=0.85, p=0.425$, $\eta^{2}=0.007$; as well as body mass index, $F(2,251)=2.66, p=0.071, \eta^{2}=0.021$. However, statistical significance was found for a following plant-based diet, $t(154)=2.37, p=0.019$, Cohen's $d=0.45$. 
3.3. Comparison between Participants Following a Vegan Diet, Vegetarian Diet and Omnivorous Diet: One-Way Analysis of Variance

The results of the one-way ANOVA with dietary patterns (vegan diet, vegetarian diet and omnivorous diet) as an independent variable and the Three-Factor Eating Questionnaire dimensions as the outcome indicates that there is a significant group difference in cognitive restraint, $F(2,251=12.28$, $p<0.001, \eta^{2}=0.089$; emotional eating, $F(2,251)=15.07, p<0.001, \eta^{2}=0.107$ and uncontrolled eating, $F(2,251)=28.32, p<0.001, \eta^{2}=0.184$. In addition, our finding shown that there is a significant group difference in the Eating Habits Questionnaire dimensions linked to problems related to healthy eating, $F(2,251)=23.67, p<0.001, \eta^{2}=0.59$; knowledge of healthy eating, $F(2,251)=35.93, p<0.001$, $\eta^{2}=0.223$ and feeling positively about healthy eating, $F(2,251)=8.20, p<0.01, \eta^{2}=0.61$. Whereas, there are no significant differences between the groups in the dimensions of the Perseverative Thinking Questionnaire namely: core features of repetitive negative thinking, $F(2,251)=0.34, p=0.709, \eta^{2}=0.03$; unproductive of repetitive negative thinking, $F(2,251)=1.02, p=0.362, \eta^{2}=0.008$ and capturing mental capacity, $F(2,251)=0.37, p=0.688, \eta^{2}=0.003$ (Table 4).

To sum up, individuals following a plant-based diet have a significantly lower levels of cognitive restraint, lower levels of emotional eating and lower levels of uncontrolled eating than individuals following an omnivorous diet. However, they are more likely to engage in cognitions, behaviours and feelings related to an extreme focus on healthy eating (orthorexia nervosa) compared to individuals following an omnivorous diet. 
Table 4. The mean (M) (and standard deviation; SD) eating behaviours, orthorexia nervosa and repetitive negative thinking across the dietary patterns.

\begin{tabular}{|c|c|c|c|c|c|c|c|c|c|c|}
\hline \multirow[t]{2}{*}{ Variable } & \multicolumn{2}{|c|}{$\begin{array}{l}\text { Vegan Diet } \\
\qquad(N=47)\end{array}$} & \multicolumn{2}{|c|}{$\begin{array}{l}\text { Vegetarian Diet } \\
\qquad(N=100)\end{array}$} & \multicolumn{2}{|c|}{$\begin{array}{l}\text { Omnivorous Diet } \\
\quad(N=107)\end{array}$} & \multirow{2}{*}{$\begin{array}{c}\begin{array}{c}\text { Vegan vs. } \\
\text { Vegetarian } \\
\text { Diet }\end{array} \\
p \text {-Value }\end{array}$} & \multirow{2}{*}{$\begin{array}{c}\begin{array}{c}\text { Vegan vs. } \\
\text { Omnivorous } \\
\text { Diet }\end{array} \\
p \text {-Value }\end{array}$} & \multirow{2}{*}{$\begin{array}{c}\begin{array}{c}\text { Vegetarian vs. } \\
\text { Omnivorous } \\
\text { Diet }\end{array} \\
p \text {-Value }\end{array}$} & \multirow{2}{*}{$\begin{array}{c}\begin{array}{c}\text { Vegan vs. } \\
\text { Vegetarian vs. } \\
\text { Omnivorous Die }\end{array} \\
p \text {-Value }\end{array}$} \\
\hline & $\begin{array}{c}\mathrm{M} \\
\text { (SD) }\end{array}$ & $95 \% \mathrm{CI}[\mathrm{LL}, \mathrm{UL}]$ & $\begin{array}{c}\mathrm{M} \\
\text { (SD) }\end{array}$ & $95 \%$ CI $[\mathrm{LL}, \mathrm{UL}]$ & M (SD) & $95 \%$ CI [LL; UL] & & & & \\
\hline Cognitive restraint & $5.70(3.54)$ & $0.51,4.66$ & $6.81(3.58)$ & $0.35,6.09$ & $8.64(3.86)$ & $0.37,7.90$ & 0.275 & 0.000 & 0.001 & 0.000 \\
\hline Uncontrolled eating & $5.48(5.10)$ & $0.74,3.99$ & $7.34(5.22)$ & $0.52,6.30$ & $12.39(7.08)$ & $0.68,11.03$ & 0.275 & 0.000 & 0.001 & 0.000 \\
\hline Emotional eating & $2.38(2.82)$ & $0.41,1.55$ & $2.85(2.70)$ & $0.27,2.31$ & $4.71(3.17)$ & $0.30,4.11$ & 1.00 & 0.000 & 0.001 & 0.000 \\
\hline $\begin{array}{c}\text { Core characteristics of repetitive } \\
\text { negative thinking }\end{array}$ & $22.57(8.57)$ & $20.05,25.09$ & $23.85(8.79)$ & $22.10,25.59$ & $23.25(9.09)$ & $0.87,21.50$ & 1.00 & 1.00 & 1.00 & 0.709 \\
\hline $\begin{array}{l}\text { Unproductiveness of repetitive } \\
\text { negative thinking }\end{array}$ & $6.57(2.77)$ & $0.40,5.75$ & $6.73(2.69)$ & $0.26,6.19$ & $7.16(2.80)$ & $0.27,6.63$ & 1.00 & 1.00 & 1.00 & 0.362 \\
\hline Capturing mental capacity & $6.40(3.31)$ & $0.48,5.43$ & $6.76(2.80)$ & $0.28,6.20$ & $6.85(3.10)$ & $0.30,6.26$ & 1.00 & 0.659 & 0.763 & 0.688 \\
\hline Knowledge of healthy eating & $14.38(3.28)$ & $0.47,13.41$ & $12.48(2.63)$ & $0.26,11.95$ & $10.13(3.23)$ & $0.31,9.51$ & 0.001 & 0.000 & 0.000 & 0.000 \\
\hline $\begin{array}{l}\text { Problems associated with } \\
\text { healthy eating }\end{array}$ & $22.87(4.76)$ & $0.69,21.47$ & $20.24(4.03)$ & $0.40,19.43$ & $17.30(5.49)$ & $0.53,16.25$ & 0.007 & 0.000 & 0.000 & 0.000 \\
\hline $\begin{array}{l}\text { Feeling positively about } \\
\text { healthy eating }\end{array}$ & $11.40(2.80)$ & $0.40,10.58$ & $10.81(2.65)$ & $0.26,10.28$ & $9.66(2.75)$ & $0.26,9.13$ & 0.656 & 0.001 & 0.008 & 0.000 \\
\hline
\end{tabular}

M: mean; SD: standard deviation; 95\% CI [LL, UL]: 95\% confidence interval [LL: lower limit of a confidence interval, UL: upper limit of a confidence interval]. Post hoc tests with Bonferroni correction were used. Significant $p$-values are shown in boldface type $(p<0.05)$. 
3.4. Relationship between Cognitive Restraint and Orthorexia Nervosa and Repetitive Negative Thinking Across the Dietary Patterns: The Pearson Correlation Coefficient

The structural relationships between cognitive restraint and orthorexia nervosa and repetitive negative thinking are presented in Table 5.

Table 5. Relationships among variables across the dietary patterns.

\begin{tabular}{|c|c|c|c|c|c|c|}
\hline \multirow{3}{*}{ Variable } & \multicolumn{2}{|c|}{$\begin{array}{l}\text { Vegan Diet } \\
(N=47)\end{array}$} & \multicolumn{2}{|c|}{$\begin{array}{l}\text { Vegetarian Diet } \\
\qquad(N=100)\end{array}$} & \multicolumn{2}{|c|}{$\begin{array}{l}\text { Omnivorous Diet } \\
\quad(N=107)\end{array}$} \\
\hline & \multicolumn{6}{|c|}{ Cognitive Restraint } \\
\hline & $r$ & $p$-Value & $r$ & $p$-Value & $r$ & $p$-Value \\
\hline Core characteristics of repetitive negative thinking & 0.325 & 0.026 & -0.62 & 0.537 & 0.241 & 0.013 \\
\hline Unproductiveness of repetitive negative thinking & 0.102 & 0.497 & 0.003 & 0.976 & 0.192 & 0.048 \\
\hline Capturing mental capacity & 0.036 & 0.808 & -0.037 & 0.716 & 0.214 & 0.027 \\
\hline Knowledge of healthy eating & 0.051 & 0.733 & 0.288 & 0.004 & 0.461 & 0.000 \\
\hline Problems associated with healthy eating & 0.336 & 0.021 & 0.273 & 0.006 & 0.505 & 0.000 \\
\hline Feeling positively about healthy eating & 0.266 & 0.70 & 0.393 & 0.000 & 0.507 & 0.000 \\
\hline
\end{tabular}

Significant values of the correlation coefficients $(r)$ are shown in boldface type $(p<0.05)$.

In vegans, cognitive restraint is related to core characteristics of repetitive negative thinking and cognitions related to orthorexia nervosa. In vegetarians, cognitive restraint is correlated to cognitions, behaviours and feelings related to orthorexia nervosa. While, in individuals adhering to an omnivorous diet cognitive restraint is associated with all dimension of repetitive negative thinking and all dimension of orthorexia nervosa.

\subsection{Predictors of Cognitive Restraint among Individuals with Varying Dietary Patterns: $\alpha$ Multiple} Linear Regression

In order to investigate determinants of cognitive restraint among adults with varying dietary patterns a multiple linear regression analysis was used (Table 6).

Table 6. Determinants of cognitive restraint in adults with varying dietary patterns.

\begin{tabular}{|c|c|c|c|c|c|}
\hline Cognitive Restraint among Vegans & $\beta$ & $t$ & $p$-Value & $R^{2}$ & $\Delta R^{2}$ \\
\hline Core characteristics of repetitive negative thinking & 1.004 & 3.763 & 0.001 & \multirow{6}{*}{0.364} & \multirow{6}{*}{0.269} \\
\hline Unproductiveness of repetitive negative thinking & -0.460 & -1.575 & 0.123 & & \\
\hline Capturing mental capacity & -0.492 & -1.981 & 0.055 & & \\
\hline Knowledge of healthy eating & -0.051 & -0.359 & 0.721 & & \\
\hline Problems associated with healthy eating & 0.111 & 0.718 & 0.477 & & \\
\hline Feeling positively about healthy eating & 0.254 & 1.148 & 0.146 & & \\
\hline Cognitive restraint among vegetarians & $\beta$ & $t$ & $p$-Value & $R^{2}$ & $\Delta R^{2}$ \\
\hline Core characteristics of repetitive negative thinking & -0.114 & -0.723 & 0.471 & \multirow{6}{*}{0.191} & \multirow{6}{*}{0.139} \\
\hline Unproductiveness of repetitive negative thinking & 0.145 & 0.997 & 0.331 & & \\
\hline Capturing mental capacity & -0.030 & -0.185 & 0.854 & & \\
\hline Knowledge of healthy eating & 0.115 & 1.052 & 0.296 & & \\
\hline Problems associated with healthy eating & 0.100 & 0.907 & 0.367 & & \\
\hline Feeling positively about healthy eating & 0.310 & 2.874 & 0.005 & & \\
\hline Cognitive restraint among non-vegetarians & $\beta$ & $t$ & $p$-Value & $R^{2}$ & $\Delta R^{2}$ \\
\hline Core characteristics of repetitive negative thinking & 0.068 & 0.395 & 0.694 & \multirow{6}{*}{0.364} & \multirow{6}{*}{0.325} \\
\hline Unproductiveness of repetitive negative thinking & 0.005 & 0.035 & 0.972 & & \\
\hline Capturing mental capacity & 0.084 & 0.541 & 0.590 & & \\
\hline Knowledge of healthy eating & 0.182 & 1.510 & 0.134 & & \\
\hline Problems associated with healthy eating & 0.241 & 2.294 & 0.024 & & \\
\hline Feeling positively about healthy eating & 0.243 & 2.142 & 0.035 & & \\
\hline
\end{tabular}

Significant $\beta^{\prime}$ s are shown in boldface type $(p<0.05)$. Participants following a vegan diet: $F$ change $(6,40)=3.818$, $p=0.004$; participants following a vegetarian diet: $F$ change $(6,93)=3.657, p=0.003$; participants following an omnivorous diet: $F$ change $(6,100)=9.519, p=0.000 . \Delta R^{2}$ : the change in $R^{2}$. 
As shown in Table 6, higher levels of repetitiveness, intrusiveness and difficulties to disengage from repetitive negative thinking predict cognitive restraint in vegans. Positive feelings related to orthorexia nervosa predict cognitive restraint in vegetarians. However, problems associated with healthy eating and feeling positively about healthy eating predict cognitive restraint in individuals following an omnivorous diet.

\section{Discussion}

The current study was designed to determine whether differences in cognitive restraint and other disordered eating patterns exist between individuals adhering to plant-based diet (vegan and vegetarian diet) and those adhering to an omnivorous diet.

Our results demonstrated that both vegetarians and vegans endorse significantly lower cognitive restraint, lower emotional eating and lower uncontrolled eating in comparison to those who followed an omnivorous diet. These results confirm our hypothesis (H1). Our findings are similar to previous study founding that restricting food intake for purposes of weight control was significantly higher in individuals following an omnivorous diet compared with those following a vegetarian diet $[12,15,18]$. In non-vegetarians, cognitive restraint could counteract the effects of overconsuming (attempts to control intake may be activated by the desire to undertake weight-loss dieting and, therefore, higher restraint may be a marker for the adverse appetitive traits or overeating tendencies), whereas in vegetarians and vegans, the overeating tendency is nearly absent and cognitive restraint may results in eating less (because they are used to restricting the amount and quality of food consumed) $[9,12]$. Vegetarians and vegans appear to have the healthiest attitudes towards food. However, we still do not know whether or not a vegetarian diet could actually serve as a protective factor against developing disordered eating [35]. It may be assumed that higher restraint scores in non-vegetarians can be interpreted as indications of disordered eating or maladaptive attitudes towards food.

Our results are consistent with a previous study [35] showing that vegans and vegetarians scored significantly lower than non-vegetarians on external eating. In our study, non-vegetarians showed higher emotional eating than vegetarians and vegans. This could potentially means that they learned to associate food and mood and then craved food when in a low-mood state or they could use food as a coping mechanism during low mood [6]. The second explanation could be that eating a favourite food had the propensity to release endogenous opioids and finally elevated their mood [6]. In our explanation the most dominant theory on emotional eating, the Macht five-way model [43], can be also useful. This model describes five way that explain how emotions affect eating: (1) emotions aroused by food stimuli affect food choice (emotions alter food choice through initiating cravings); (2) emotions high in arousal or intensity suppress eating (due to incompatible emotional responses); (3) emotions moderate in arousal or intensity affect eating depending on motivations to eat (in emotional eating, negative emotions elicit the tendency to be regulated by eating and, as a consequence, enhance intake of sweet and high-fat foods); (4) emotions consume cognitive resources, therefore individuals who use cognitive resources to govern what to eat will struggle to maintain those rules under emotional load; (5) emotions provide a feedback loop and interact with food to increase or decrease its pleasantness depending on the strength and orientation of the mood [43].

In addition, our findings show that both groups following a plant-based diet show more cognitions, behaviours and feelings related to an extreme focus on healthy eating defined as orthorexia nervosa (greater problems related to healthy eating, greater knowledge of healthy eating and greater positive feelings regarding healthy eating) than groups following an omnivorous diet. This suggests that individuals with orthorexia nervosa tendencies are more likely to be on a vegetarian and a vegan diet. Hypothesis 2 was confirmed. Previous studies have demonstrated similar results using the same questionnaire (the Three-Factor Eating Questionnaire) [12,37,42]. Other studies (using other methods assessing orthorexia nervosa) have also found that vegetarians and vegans were more likely than omnivores to display orthorexia nervosa $[16,44,45]$. Adhering to plant-based diets could prompt more focus on the quality of food (main core of orthorexia nervosa) and food consumption which may indicate 
that vegetarians and vegans are more likely to suffer from orthorexia nervosa or be at risk of developing orthorexia nervosa [15]. It is worth pointing out that previous studies found that vegetarians tend to demonstrate a higher level of nutrition knowledge than non-vegetarians [46] and showed a greater desire for more, improved information to apply to their eating habits [47]. However, as DeMay et al. [48] states, most data were based on vegetarian-related questions. Preliminary evidence suggests that vegetarians are generally more health-focused and vegans are more likely to be health-conscious than omnivores [49]. Many vegetarians follow healthy lifestyle patterns in greater frequency than non-vegetarians [50], however in some individuals, interest in healthy attitudes and behaviors towards food may show obsessive signs [19] and leads to orthorexia nervosa.

Our findings showed that vegetarians, vegans and non-vegetarians do not differ in perseverant thinking. Thus, there is no difference between these groups in core characteristics of repetitive negative thinking, unproductiveness of repetitive negative thinking and the degree to which repetitive negative thinking captures mental capacity. This would suggest that these three groups presented a similar level of repetitive negative thinking.

Our findings show that in vegans, cognitive restraint was associated with core characteristics of repetitive negative thinking and cognitions related to orthorexia nervosa. Cognitive restraint prevents food intake that is related to negative emotional content [51] and can lead to increased negative thoughts. Because both orthorexia nervosa and cognitive restraint shares a key component -self-imposed restriction of allowed food [12], it is not surprising that evidence has been found for a link between cognitive restraint and orthorexia nervosa in individuals following a plant-based diet (in vegetarians, cognitive restraint is correlated to cognitions, behaviours and feelings related to orthorexia nervosa). In individuals adhering to an omnivorous diet cognitive restraint was associated with all dimension of repetitive negative thinking and all dimension of orthorexia nervosa. This indicates that increased mental effort applied to modify eating behaviours in order to maintain a restrictive dietary pattern is related to higher levels of repetitiveness of repetitive negative thinking, intrusiveness of repetitive negative thinking, difficulties to disengage from repetitive negative thinking, unproductiveness of repetitive negative thinking and capturing mental capacity as well as higher levels of extreme focus on healthy eating.

The second objective of the present study was to identify the determinants of cognitive restraint among adults with varying dietary patterns. The results partially confirmed our hypotheses (H3 and H4) Regression analyses revealed that higher levels of the core characteristics of repetitive negative thinking (repetitiveness, intrusiveness, difficulties to disengage) predicted cognitive restraint in vegans. This means that perseverant thinking leads vegans to exacerbate their restricting food intake for purposes of weight control. It is worth adding that previous (experimental) study has shown that suppressing food-related thoughts can cause a subsequent increase in consumption relative to individuals not suppressing or thinking about food [52]. Participants showing high levels of dietary restraint in the suppression condition consumed significantly more chocolate than those showing high levels of dietary restraint in the expression or control condition. In addition, participants reporting frequent use of thought suppression reported greater chocolate cravings [52]. It can be presumed that vegans do not suppress their food-related thoughts and therefore they restrict the amount and quality of food consumed. The second explanation could be that enduring negative thoughts signal a cognitive conflict that leads to the disengagement of attention from negative thoughts via attentional control. From this perspective, repetitive negative thinking results from impaired cognitive conflict signaling and/or difficulties in enacting attentional control to divert attention away from one's negative thoughts [53]. It is worth emphasizing that inducing repetitive negative thinking in non-clinical samples has been shown to negatively impact cognitive, behavioral, and interpersonal performance [54]. Our results demonstrate that repetitive negative thinking influences increased cognitive restraint in vegans. Positive feelings related to an extreme focus on healthy eating (orthorexia nervosa) were a significant predictor of cognitive restraint in vegetarians. Positive feelings related to orthorexia nervosa are characterized by: feeling in control, feeling a sense of satisfaction in eating 
healthily, and feeling great and peaceful after eating healthily [37]. There is increasing evidence that a daily diet rich in fruits and vegetables is associated with greater positive affect, positive mood, happiness, and life satisfaction [55]. Recent studies have suggested that high fruit and vegetable consumption may be a causal factor in promoting states of positive well-being and eudaemonic well-being as well $[55,56]$. Dietary cognitive restraint has been also shown to be positively associated with self-reported consumption of healthy foods [57]. Based on these results, it could be supposed that adhering to a vegetarian diet may be related with positive feelings and lead to conscious restriction of food intake in order to control body weight or to promote weight loss. Our results show that problems associated with healthy eating and feeling positively about healthy eating predicted cognitive restraint in individuals following an omnivorous diet. Problems associated with healthy eating are characterized by: often turning down social events that involve eating unhealthy food, following a diet with many rules, being distracted by thoughts of eating healthily, considering one's own healthy eating as a source of stress in a relationship, having difficulty finding restaurants that serve healthy food and food restrictions [37]. We can suppose that in these individuals cognitive restraint can be offset by inappropriate eating patterns leading to increased orthorexia nervosa.

Some limitations of the present study should be noted. First, the cross-sectional nature of the data means no conclusion can be drawn regarding the causation of our findings. For investigating the causality, the future study should be focused on experimental and longitudinal studies. Second, there are unequal sample sizes across the plant-based diet groups. Greater numbers in each group (particularly in vegan group) would increase statistical power and the strength of conclusions. Third, body measurements are subjective. Although self-measurement values have been found to be valid and reliable when compared to direct measurements, discrepancies do still occur when those measurements are compared with objective measurement methods [58]. It is worth pointing out that previous results have shown that women and men have a tendency to overestimate their height and to underestimate their weight (the underestimation of weight is more pronounced in women [58]). Therefore, objectively measured body mass index should be considered to avoid inaccurate estimation of body weight and height. Finally, current sample data provide limited information on sociodemographic characteristics. More detailed information on sociodemographic characteristics of the samples (e.g., information on occupation, education, income, being pregnant) should be available for providing better knowledge of the sociodemographic profiles of self-reported vegetarians and vegans (nowadays there are few published studies on sociodemographic characteristics of those groups [59]).

\section{Conclusions}

Our results indicated that both vegetarian and vegan groups showed a significantly lower cognitive restraint, lower emotional eating, and lower uncontrolled eating than those who followed an omnivorous diet. Our results are compatible with findings demonstrating that individuals following a plant-based diet (vegetarians and vegans) show more cognitions, behaviours and feelings related to orthorexia nervosa than a group following an omnivorous diet.

This study was the first to explore predictors of conscious restriction of food intake in order to control body weight or to promote weight loss of individuals following different dietary patterns. Longitudinal examinations confirming our findings are needed. Nevertheless, knowledge of predictors of cognitive restraint (repetitive negative thinking and orthorexia nervosa) may serve as a psychological intervention goal or psychoeducation goal among individuals with varying dietary patterns. In addition, healthcare professionals should keep repetitive negative thinking and orthorexia nervosa status in mind when dealing with individuals adhering to a vegan and vegetarian dietary patterns. The development of interventions designed to reduce levels of negative thoughts among individuals with high levels of cognitive restraint could be helpful to end or struggle with perseverant thinking or cognitive distortions that can lead to disordered eating behaviours (e.g., orthorexia nervosa). The present study provides information about the determinants of the cognitive restraint by suggesting that this construct is linked with orthorexia nervosa among individuals with varying dietary patterns and with repetitive negative 
thinking among individuals following a vegan diet. Our findings concerning the predictors of cognitive restraint could lead to effective measures, e.g., for identifying at-risk individuals. Furthermore, our results could serve as a starting point for future studies.

There are a number of gaps in our knowledge around cognitive restraint. The existing research on cognitive restraint and varying dietary patterns (especially a vegetarian diet) is cross-sectional, so causality cannot be determined. Therefore, more research is needed in this area. Future research should track cognitive restraint and other disordered eating patterns among individuals varying dietary patterns longitudinally to determine cause and effect.

Funding: This research was funded by National Science Centre (NCN), Poland, grant number 2017/01/X/HS6/00007.

Acknowledgments: I am grateful to EAT Lab members for their help with data collection.

Conflicts of Interest: The author declares no conflict of interest. The founding sponsors had no role in the design of the study; in the collection, analyses, or interpretation of data; in the writing of the manuscript; and in the decision to publish the results.

\section{References}

1. U.S. Department of Health and Human Services and U.S. Department of Agriculture. 2015-2020 Dietary Guidelines for Americans, 8th ed. December 2015. Available online: http://health.gov/dietaryguidelines/ 2015/guidelines/ (accessed on 20 March 2020).

2. Petti, A.; Palmieri, B.; Vadalà, M.; Laurino, C. Vegetarianism and veganism: Not only benefits but also gaps. A review. Progr. Nutr. 2017, 19, 229-242. [CrossRef]

3. Larsson, C.L.; Rönnlund, U.; Johansson, G.; Dahlgren, L. Veganism as status passage: The process of becoming a vegan among youths in Sweden. Appetite 2003, 41,7-61. [CrossRef]

4. Janssen, M.; Busch, C.; Rödiger, M.; Hamm, U. Motives of consumers following a vegan diet and their attitudes towards animal agriculture. Appetite 2016, 105, 643-651. [CrossRef] [PubMed]

5. Heiss, S.; Hormes, J.M.; Timko, C.A. Vegetarianism and Eating Disorders; Elsevier BV: Amsterdam, The Netherlands, 2017; pp. 51-69.

6. Dovey, T.M. The psychology of eating. In Reference Module in Neuroscience and Biobehavioral Psychology; Elsevier BV: Amsterdam, The Netherlands, 2017.

7. Herman, C.P.; Polivy, J. A boundary model for the regulation of eating. Res. Publ. Assoc. Res. Nerv. Ment. Dis. 1984, 62, 141-156. [CrossRef] [PubMed]

8. Lowe, M.R. The effects of dieting on eating behavior: A three-factor model. Psychol. Bull. 1993, 114, $100-121$. [CrossRef]

9. Johnson, F.; Pratt, M.; Wardle, J. Dietary restraint and self-regulation in eating behavior. Int. J. Obes. 2011, 36, 665-674. [CrossRef]

10. Norwood, R.; Cruwys, T.; Chachay, V.S.; Sheffield, J. The psychological characteristics of people consuming vegetarian, vegan, paleo, gluten free and weight loss dietary patterns. Obes. Sci. Pract. 2019, 5, 148-158. [CrossRef]

11. Barr, S.I.; Janelle, K.C.; Prior, J.C. Vegetarian vs nonvegetarian diets, dietary restraint, and subclinical ovulatory disturbances: Prospective 6-mo study. Am. J. Clin. Nutr. 1994, 60, 887-894. [CrossRef]

12. Brytek-Matera, A. Interaction between vegetarian versus omnivorous diet and unhealthy eating patterns (orthorexia nervosa, cognitive restraint) and body mass index in adults. Nutrients 2020, 12, 646. [CrossRef]

13. Barr, S.I.; Broughton, T.M. Relative weight, weight loss efforts and nutrient intakes among health-conscious vegetarian, past vegetarian and nonvegetarian women ages 18 to 50. J. Am. Coll. Nutr. 2000, 19, 781-788. [CrossRef]

14. Gilbody, S.M.; Kirk, S.F.; Hill, A.J. Vegetarianism in young women: Another means of weight control? Int. J. Eat. Disord. 1999, 26, 87-90. [CrossRef]

15. Curtis, M.J.; Comer, L.K. Vegetarianism, dietary restraint and feminist identity. Eat. Behav. 2006, 7, 91-104. [CrossRef] [PubMed]

16. Barthels, F.; Meyer, F.; Pietrowsky, R. Orthorexic and restrained eating behaviour in vegans, vegetarians, and individuals on a diet. Eat. Weight Disord. 2018, 23, 159-166. [CrossRef] 
17. Martins, Y.; Pliner, P.; O'Connor, R. Restrained eating among vegetarians: Does a vegetarian eating style mask concerns about weight? Appetite 1999, 32, 145-154. [CrossRef] [PubMed]

18. Janelle, K.C.; Barr, S.I. Nutrient intakes and eating behavior scores of vegetarian and nonvegetarian women. J. Am. Diet. Assoc. 1995, 95, 180-189. [CrossRef]

19. Brytek-Matera, A.; Czepczor-Bernat, K.; Jurzak, H.; Kornacka, M.; Kołodziejczyk, N. Strict health-oriented eating patterns (orthorexic eating behaviours) and their connection with a vegetarian and vegan diet. Eat. Weight Disord. 2018, 24, 441-452. [CrossRef]

20. McLean, J.A.; Barr, S.I. Cognitive dietary restraint is associated with eating behaviors, lifestyle practices, personality characteristics and menstrual irregularity in college women. Appetite 2003, 40, 185-192. [CrossRef]

21. Fisak, B.; Peterson, R.D.; Tantleff-Dunn, S.; Molnar, J.M. Challenging previous conceptions of vegetarianism and eating disorders. Eat. Weight Disord. 2006, 11, 195-200. [CrossRef]

22. Trautman, J.; Rau, S.I.; Wilson, M.A.; Walters, C. Vegetarian students in their first year of college. Are they at risk for restrictive or disordered eating behavior? Coll. Stud. J. 2008, 42, 340-347.

23. Forestell, C.A.; Spaeth, A.M.; Kane, S.A. To eat or not to eat red meat. A closer look at the relationship between restrained eating and vegetarianism in college females. Appetite 2012, 58, 319-325. [CrossRef]

24. Worsley, A.; Skrzypiec, G. Teenage vegetarianism: Prevalence, social and cognitive contexts. Appetite 1998, 30, 151-170. [CrossRef]

25. Dunn, T.M.; Bratman, S.V. On orthorexia nervosa: A review of the literature and proposed diagnostic criteria. Eat. Behav. 2016, 21, 11-17. [CrossRef]

26. Bratman, S. Health food junkie. Yoga J. 1997, 136, 42-50.

27. Syurina, E.V.; Bood, Z.M.; Ryman, F.V.M.; Muftugil-Yalcin, S. Cultural phenomena believed to be associated with orthorexia nervosa-opinion study in dutch health professionals. Front. Psychol. 2018, 9, 1419. [CrossRef]

28. Koven, N.; Abry, A.W. The clinical basis of orthorexia nervosa: Emerging perspectives. Neuropsychiatr. Dis. Treat. 2015, 11, 385-394. [CrossRef]

29. Dell'Osso, L.; Abelli, M.; Carpita, B.; Massimetti, G.; Pini, S.; Rivetti, L.; Gorrasi, F.; Tognetti, R.; Ricca, V.; Carmassi, C. Orthorexia nervosa in a sample of Italian university population. Riv. Psichiatr. 2016, 51, 190-196.

30. Barnes, M.A.; Caltabiano, M.L. The interrelationship between orthorexia nervosa, perfectionism, body image and attachment style. Eat. Weight Disord. 2017, 22, 177-184. [CrossRef]

31. Brytek-Matera, A. Vegetarian diet and orthorexia nervosa: A review of the literature. Eat. Weight Disord. 2019, 29, 1-11. [CrossRef]

32. Brytek-Matera, A. Orthorexia nervosa-an eating disorder, obsessive-compulsive disorder or disturbed eating habit? Arch. Psychiatry Psychother. 2012, 14, 55-60.

33. Ehring, T.; Zetsche, U.; Weidacker, K.; Wahl, K.; Schönfeld, S.; Ehlers, A. The perseverative thinking questionnaire (PTQ): Validation of a content-independent measure of repetitive negative thinking. J. Behav. Ther. Exp. Psychiatry 2011, 42, 225-232. [CrossRef]

34. Nezlek, J.B.; Forestell, C.A.; Newman, D.B. Relationships between vegetarian dietary habits and daily well-Being. Ecol. Food Nutr. 2018, 57, 1-14. [CrossRef] [PubMed]

35. Timko, C.A.; Hormes, J.M.; Chubski, J.; Timko, C.A. Will the real vegetarian please stand up? An investigation of dietary restraint and eating disorder symptoms in vegetarians versus non-vegetarians. Appetite 2012, 58, 982-990. [CrossRef]

36. Eysenbach, G.; Wyatt, J.C.; McKenzie, B. Using the internet for surveys and health research. J. Med. Internet Res. 2002, 4, 13. [CrossRef] [PubMed]

37. Karlsson, J.; Persson, L.O.; Sjöström, L.; Sullivan, M. Psychometric properties and factor structure of the Three-Factor Eating Questionnaire (TFEQ) in obese men and women. Results from the Swedish Obese Subjects (SOS) study. Int. J. Obes. 2000, 24, 1715-1725. [CrossRef] [PubMed]

38. Gleaves, D.; Graham, E.C.; Ambwani, S. Measuring "orthorexia:" development of the Eating Habits Questionnaire. Int. J. Educ. Psychol. Assess. 2013, 12, 1-18.

39. Brytek-Matera, A.; Rogoza, R.; Czepczor-Bernat, K. The Three-Factor Eating Questionnaire-R18 Polish version: Factor structure analysis among normal weight and obese adult women. Arch. Psychiatry Psychother. 2017, 19, 81-90. [CrossRef]

40. Kornacka, M.; Buczny, J.; Layton, R.L. Assessing repetitive negative thinking using categorical and transdiagnostic approaches: A Comparison and validation of three Polish language adaptations of self-report questionnaires. Front. Psychol. 2016, 7, 322. [CrossRef] 
41. Nawrocka, A.; Mynarski, W. Objective assessment of adherence to global recommendations on physical activity for health in relation to spirometric values in nonsmoker women aged 60-75 years. J. Aging Phys. Act. 2017, 25, 123-127. [CrossRef]

42. IPAQ Research Committee. Guidelines for Data Processing and Analysis of the International Physical Activity Questionnaire (IPAQ)—Short and Long Forms; Karolinska Institutet: Stockholm, Sweden, 2005.

43. Macht, M. How emotions affect eating: A five-way model. Appetite 2008, 50, 1-11. [CrossRef]

44. Chard, C.; Hilzendegen, C.; Barthels, F.; Stroebele-Benschop, N. Psychometric evaluation of the English version of the Düsseldorf Orthorexie Scale (DOS) and the prevalence of orthorexia nervosa among a U.S. Student Sample. Eat. Weight Disord. 2018, 24, 275-281. [CrossRef]

45. Dittfeld, A.; Gwizdek, K.; Jagielski, P.; Brzęk, J.; Ziora, K. A study on the relationship between orthorexia and vegetarianism using the BOT (Bratman Test for Orthorexia). Psychiatr. Pol. 2017, 51, 1133-1144. [CrossRef] [PubMed]

46. Leonard, A.J.; Chalmers, K.; Collins, C.E.; Patterson, A.J. The effect of nutrition knowledge and dietary iron intake on iron status in young women. Appetite 2014, 81, 225-231. [CrossRef] [PubMed]

47. Hoffman, S.; Stallings, S.F.; Bessinger, R.C.; Brooks, G.T. Differences between health and ethical vegetarians: Strength of conviction, nutrition knowledge, dietary restriction, and duration of adherence. Appetite 2013, 65, 139-144. [CrossRef]

48. DeMay, T.D.; Nnakwe, N.E.; Yu, U.; Schumacher, J.A. Examination of nutrition knowledge, attitude, and dietary behaviors of college student vegetarians, semi-vegetarians, and non-vegestarians. Sci. J. Food Sci. Nutr. 2019, 5, 6-14.

49. Heiss, S.; Coffino, J.A.; Hormes, J.M. Eating and health behaviors in vegans compared to omnivores: Dispelling common myths. Appetite 2017, 118, 129-135. [CrossRef]

50. Parker, H.W.; Vadiveloo, M.K. Diet quality of vegetarian diets compared with nonvegetarian diets: A systematic review. Nutr. Rev. 2019, 77, 144-160. [CrossRef]

51. Ling, P.R. Trends in Obesity Research; Nova Publishers: New York, NY, USA, 2005.

52. Erskine, J.A.K.; Georgiou, G. Effects of thought suppression on eating behaviour in restrained and non-restrained eaters. Appetite 2010, 54, 499-503. [CrossRef]

53. Lydon-Staley, D.M.; Kuehner, C.; Zamoscik, V.E.; Huffziger, S.; Kirsch, P.; Bassett, D.S. Repetitive negative thinking in daily life and functional connectivity among default mode, fronto-parietal, and salience networks. Transl. Psychiatry 2019, 9, 234. [CrossRef]

54. Watkins, E. Constructive and unconstructive repetitive thought. Psychol. Bull. 2008, 134, 163-206. [CrossRef]

55. Conner, T.S.; Brookie, K.L.; Richardson, A.C.; Polak, M.A. On carrots and curiosity: Eating fruit and vegetables is associated with greater flourishing in daily life. Br. J. Health Psychol. 2014, 20, 413-427. [CrossRef]

56. Brookie, K.L.; Best, G.I.; Conner, T.S. Intake of raw fruits and vegetables is associated with better mental health than intake of processed fruits and vegetables. Front. Psychol. 2018, 9, 487. [CrossRef] [PubMed]

57. Masterson, T.D.; Brand, J.; Lowe, M.R.; Metcalf, S.A.; Eisenberg, I.W.; Emond, J.A.; Gilbert-Diamond, D.; Marsch, L.A. Relationships among dietary cognitive restraint, food preferences, and reaction times. Front. Psychol. 2019, 10, 2256. [CrossRef] [PubMed]

58. Olfert, M.D.; Barr, M.L.; Charlier, C.M.; Famodu, O.A.; Zhou, W.; Mathews, A.E.; Byrd-Bredbenner, C.; Colby, S. Self-reported vs. measured height, weight, and BMI in young adults. Int. J. Environ. Res. Public Health 2018, 15, 2216. [CrossRef] [PubMed]

59. Allès, B.; Baudry, J.; Méjean, C.; Touvier, M.; Péneau, S.; Hercberg, S.; Kesse-Guyot, E. Comparison of sociodemographic and nutritional characteristics between self-reported vegetarians, vegans, and meat-eaters from the NutriNet-Santé study. Nutrients 2017, 9, 1023. [CrossRef]

(C) 2020 by the author. Licensee MDPI, Basel, Switzerland. This article is an open access article distributed under the terms and conditions of the Creative Commons Attribution (CC BY) license (http://creativecommons.org/licenses/by/4.0/). 